\title{
THE EFFECTS OF THE TEMPERATURES OF THE FLOOR SURFACE AND OF THE AIR ON THERMAL SENSATIONS AND THE SKIN TEMPERATURE OF THE FEET
}

BY

\author{
F. A. CHRENKO
}

\begin{abstract}
From the Environmental Hygiene Research Unit, Medical Research Council Laboratories, Hampstead, London
\end{abstract}
(RECEIVED FOR PUBLICATION APRIL 30, 1956)

A century ago the Commissioners who reported to the General Board of Health (1857) on the warming and ventilation of dwellings emphasized that in a comfortable and healthy apartment the floor should be at the highest temperature in the room. This requirement is met in rooms where the floor is warmed. Floor heating is used in Liverpool Cathedral, and Widdows (1921) applied floor heating in schools which he designed for the Derbyshire County Council. More recently the method has been used in a variety of commercial buildings and in houses. This method of heating has the great advantage of giving considerable freedom in planning, and furthermore, no heating apparatus is visible.

Floor heating must be applied with care, however, for if the floor is too hot the feet of the occupants may be overheated so that serious discomfort ensues. This is self-evident, but there seems to be much diversity of opinion concerning the limiting temperature of the surface of a warmed floor beyond which discomfort is likely to arise and limiting values quoted by different authorities vary between $75^{\circ}$ and $85^{\circ} \mathrm{F}$. It should be mentioned, also, that a risk of discomfort from overheated floors may arise in buildings warmed by means of ceiling panels, for in some such buildings the leakage of heat through the floors is considerable. Thus in a hospital so warmed nurses experienced discomfort from warmed floors. It seems that the risk of discomfort with a given floor temperature will probably vary with the posture and activity of the occupants, but information as to the magnitude of the risk of discomfort under given conditions has not hitherto been available for the guidance of engineers who are designing heating installations.

The present paper describes experiments in which persons were exposed to warmed floors. During the experiments the sensations of warmth of parts of the foot were assessed and the skin temperatures of those parts were measured. The relation between skin temperature and warmth of the foot was then determined. The effects of both the floor surface temperature and the air temperature on $(a)$ the skin temperature of the foot and $(b)$ sensations of warmth of the foot were then obtained. The percentage incidences of discomfort derived from numerical assessments of the warmth of the feet were transformed to a probit scale for purposes of analysis. The experimental subjects were men and women who in different experiments sat or walked about. From the results of the experiments it was possible to ascertain the risk of discomfort and hence the maximum desirable temperature of the surface of a heated floor for men or women who were walking and sitting.

\section{Methods}

The experiments were conducted in a laboratory $17 \frac{1}{2} \mathrm{ft}$. $\times 24 \mathrm{ft}$. in plan and $14 \mathrm{ft}$. high. Mechanical ventilation was not available, but with doors and windows closed the ventilation rate varied between one and a half and three air changes per hour, so that with but few occupants there was an ample supply of fresh air. Control of the air temperature and of the atmospheric humidity was not feasible. During experiments draughts were avoided by keeping doors and windows closed, and the effects of solar radiation through the windows were greatly reduced by large screens of aluminium foil. The temperature of the surface of a small wooden platform $9 \mathrm{ft}$. long and $5 \mathrm{ft}$. wide, which comprised the floor, was changed by varying the power supplied to electrical resistance mats fixed to the underside of the boarding.

Measurements.-Although a few preliminary measurements of air speed and atmospheric humidity were made, neither of these variables was measured systematically during the experiments. The air was calm, and moderate 
variations in humidity at normal room temperatures have but little effect on sensations of general bodily warmth, and probably none on the localized sensations with which this paper is primarily concerned. Measurements made with a radiation thermopile showed that the mean radiant temperature varied only slightly from the air temperature, so that radiation need not be considered separately here.

The air temperature was measured with copperconstantan thermojunctions situated at head level and at 6 in. above the heated portion of the floor, and similar thermojunctions embedded in the surface of the floor were used for measuring the surface temperature of the heated part of the floor. Throughout the experiments the air temperature averaged about $68^{\circ} \mathrm{F}$., but the temperatures recorded in individual experiments varied between $58^{\circ} \mathrm{F}$. and $76^{\circ} \mathrm{F}$. However, the drift in the air temperature in any one experiment was negligible.

The temperatures of the skin of a subject's foot were measured $(a)$ on the ankle, at about 1 in. below the medial malleolus; (b) on the sole, on the plantar surface of the base of the big toe; and (c) on the dorsum of the proximal end of the big toe. These sites will be referred to as the ankle, sole, and toe respectively. The measurements were made with thermojunctions of 36-gauge copper and constantan wires. The test junctions were attached to the skin by small pieces of thin plastic adhesive tape and as a rule were attached to the left foot. So that the subjects could have freedom of movement, the leads from the junctions attached to the skin were connected to the measuring apparatus only when it was desired to measure skin temperatures, and they were then connected to the appropriate terminals of a switchbox similar to that described by Lewis (1930).

Some measurements of the girth of the instep and of the ankle above the malleoli were made with the aid of mercury-in-rubber strain gauges designed by Whitney (1953). Changes in girth of the instep and the ankle were displayed simultaneously on a two-channel photographic recording galvanometer with a period of $0.2 \mathrm{sec}$.

Subjects and Experiments.- The subjects, three women and five men, sat or walked about for one hour. They wore their normal shoes and clothing. In the sitting experiments they sat in comfortable chairs with their feet resting on the heated floor, while in the other experiments they walked about slowly on the floor.*

For the numerical assessment of thermal sensations the following scale was used:-

$\left.\begin{array}{l|r}\hline \multicolumn{1}{c|}{\text { Thermal Sensation }} & \text { Numerical Mark Assigned } \\ \hline \text { Much too warm } & +3 \\ \text { Too warm } & +2\} \\ \text { Comfortably warm } & +1 \\ \text { Comfortable } & 0 \\ \text { Comfortably cool } & -1 \\ \text { Too cool } & -2 \\ \text { Much too cool } & -3\end{array}\right\}$

*An experiment, i.e., the exposure of one subject to a given floor temperature for one hour, did not begin until the subject was thermally comfortable, and it was the sensation of warmth and not the skin temperature that decided when the experiment began. There was room for three subjects on the floor, so that, for a given floor temperature, three experiments could be conducted simultaneously. Care was taken to ensure that all subjects were exposed to nearly the same range of floor temperatures.
The subjects reported their sensations of warmth with reference to $(a)$ the head, $(b)$ the whole body with the exception of the head and feet, $(c)$ the ankle, $(d)$ the sole of the foot, and $(e)$ the toe. These thermal sensations were assessed and the skin temperatures measured at the beginning, the middle, and the end of the period of exposure. The results at the end of the period of exposure were used for analysis.

Analysis of Results. - When the subjects were exposed to the heated floor the feet, and especially the soles, were liable to become uncomfortably warm, so it was appropriate to correlate the numerical marks assigned to the sensations of warmth referred to the sole of the foot with the temperature of the floor surface. In this way interesting and valuable information about trends could be obtained, but in addition it was important also to examine the frequency with which discomfort occurred at various levels of floor temperature, and for this purpose recourse was had to probit analysis (Finney, 1944, 1947; Emmens, 1948). When the recorded sensation was " too warm " or " much too warm ", i.e., +2 or +3 on the numerical scale, discomfort, but not necessarily gross discomfort, was experienced. The percentage frequency of occurrence of such discomfort at each level of floor temperature used was ascertained and these percentages were transformed into the appropriate probability units (probits). The probits were then related to floor surface temperatures and regression equations calculated. Four such equations were derived from which may be calculated the maximum desirable surface temperature of a heated floor for men or women who are sitting or walking.

These methods were also employed in studying the relation between skin temperature of the foot and thermal comfort.

\section{Results}

Incidence of Discomfort Related to Floor Temperature.-In Table 1 are set out the constants of the regression equations of the form

$$
\mathrm{y}=\mathrm{a}+\mathrm{bt}_{f}
$$

where $\mathrm{y}$ is the probit of the incidence of discomfort and $\mathrm{t}_{f}$ is the floor surface temperature in ${ }^{\circ} \mathrm{F}$.

From the equations it can be calculated that the floor surface temperatures at which the incidence of discomfort would be expected to be $50 \%$, i.e., a probit of 5.0 , are, for the women, $93^{\circ} \mathrm{F}$. when sitting and $86^{\circ} \mathrm{F}$. when walking, while the corresponding temperatures for the men are $90^{\circ} \mathrm{F}$. and $84^{\circ} \mathrm{F}$. respectively. These results suggest that the activity of the subjects is more important than the nature of the footwear so far as tolerance of a warm floor is concerned, for the differences between comparable temperatures for men and women are distinctly smaller than the differences due to activity in persons of the same sex.

The probit regression line for women subjects when walking is shown in Fig. 1.

When the subjects, both men and women, were 
TABLE 1

CONSTANTS OF PROBIT REGRESSION EQUATIONS RELATING INCIDENCE OF DISCOMFORT TO FLOOR SURFACE TEMPERATURE

\begin{tabular}{|c|c|c|c|c|}
\hline & \multicolumn{2}{|c|}{ Women Subjects } & \multicolumn{2}{|c|}{ Men Subjects } \\
\hline & Sitting & Walking & Sitting & Walking \\
\hline $\begin{array}{l}\text { a } \\
b \\
\chi^{2} \\
\text { No. of degrees of freedom } \\
\text { No. of experiments }\end{array}$ & $\begin{array}{c}-\overline{4.00} \\
+0.097 \underset{7.36}{7.020} \\
10 \\
254\end{array}$ & $\begin{array}{c}-16 \cdot 24 \\
+0.248 \pm 0.038 \\
7 \cdot 50 \\
4 \\
221\end{array}$ & $\begin{array}{c}-12.86 \\
+0.198 \\
1.46 \\
9 \\
125\end{array}$ & $\begin{array}{c}-18.08 \\
+0.275 \pm 0.041 \\
4.35 \\
7 \\
255\end{array}$ \\
\hline
\end{tabular}

walking the highest floor temperature at which no discomfort was experienced was $77^{\circ} \mathrm{F}$. According to Fig. 1 the probit of the expected percentage incidence of discomfort among women at that temperature is 2.9 , and that value represents an incidence of $1.8 \%$. According to the probit regression equation for the men when walking the expected incidence of discomfort is $2.8 \%$.

The probit regression equation for women sitting, the constants of which are shown in Table 1, gives for a floor temperature of $77^{\circ} \mathrm{F}$. a probit value which indicates that the expected incidence of discomfort would be $6.3 \%$. Similarly, the probits for men sitting show that with that floor temperature discomfort would be expected in less than $1 \%$ of the observations. In fact, during the sitting experiments no discomfort was experienced by the women until the floor temperature exceeded $77^{\circ} \mathrm{F}$., or by the men until it exceeded $79^{\circ} \mathrm{F}$.

The pressure of the foot on the floor is greater when standing than when sitting, and this firmer contact with the floor results in a decreased resistance to the transmission of heat between floor and foot. In walking there is a similar effect during the time the feet are on the floor. Hence, it might be expected

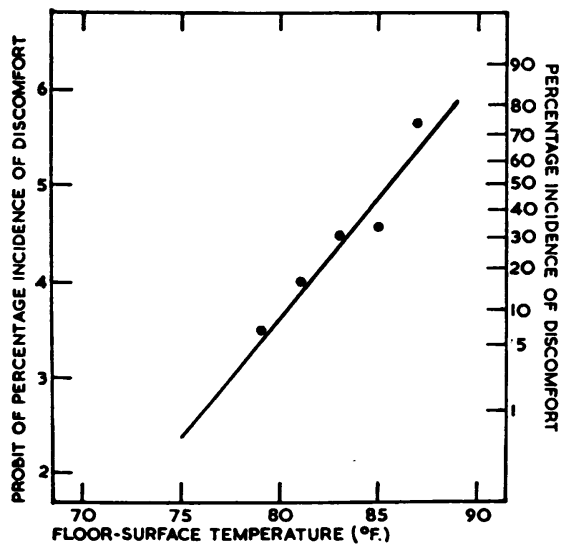

FIG 1.-Probits of the percentage incidence of uncomfortable warming of the soles of the feet in relation to the temperature of the floor surface for women subjects when walking. that with a given floor temperature discomfort would occur less frequently in sitting than in walking persons. This was so in these observations, for the floor temperatures corresponding to a $50 \%$ incidence of discomfort were substantially higher for the sitting subjects (Fig. 2).

Relation between Skin Temperature and Comfort on Different Parts of the Foot.-Correlation of the sensations of warmth referred to the ankle, sole, and toe with the skin temperatures measured on the respective sites showed that the association between sensation and skin temperature was closest in respect of the sole, hence, in further consideration of skin temperature and its relations, only the temperature of the sole will be used.

The zero-order correlations ( $r$ ) between the numerical marks assigned to the thermal sensations and the temperature of the skin of the sole were:

\begin{tabular}{|c|c|c|}
\hline Subjects and Activity & $\mathbf{r}$ & No. of Experiments \\
\hline 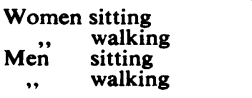 & $\begin{array}{l}+0.68 \\
+0.75 \\
+0.77 \\
+0.70\end{array}$ & $\begin{array}{l}240 \\
202 \\
121 \\
238\end{array}$ \\
\hline
\end{tabular}

For each of the coefficients the value of $P$ is less than 0.001 .

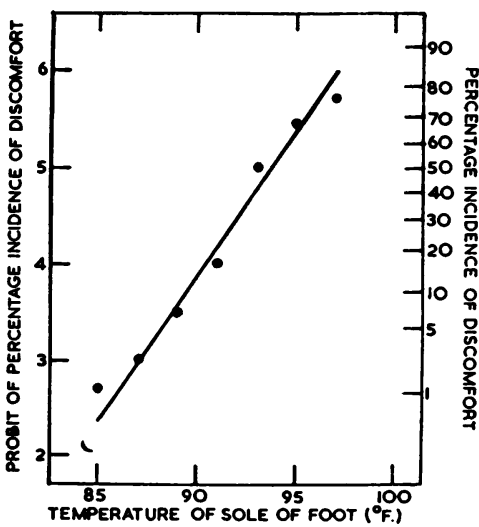

FIG. 2.-The probit of the percentage incidence of discomfort (uncomfortable warming of the sole of the foot after 60 minutes' exposure to a heated floor) plotted against the temperature $\left({ }^{\circ} \mathrm{F}\right.$.) (data from all experiments combined). 
The results of the four series of experiments were so similar that it was reasonable to pool the data and to calculate an overall regression for sensation of warmth on skin temperature. The correlation coefficient (r) was $+0.72(P<0.001)$ and the regression equation

$$
\mathrm{S}=0 \cdot 112 \mathrm{t}_{s}-8.97 \ldots \ldots \text { (i) }
$$

where $S$ is the numerical value of the sensation, and $t_{s}$ is the skin temperature on the sole in ${ }^{\circ} \mathrm{F}$.

Although the value of the correlation coefficient is high, it is not high enough to enable one to predict individual sensations of warmth with useful accuracy.

The relation between the incidence of discomfort through excessive warming of the feet and the skin temperature of the sole was also examined by the probit method. The probit regression equation was

$$
P=0.304 \mathrm{t}_{s}-23 \cdot 50 \ldots \ldots \text { (ii) }
$$

where $\mathbf{P}$ is the probit of the percentage incidence of discomfort and $t_{s}$ is the skin temperature of the sole in ${ }^{\circ} \mathrm{F}$. The standard error of the regression constant is \pm 0.023 , and the skin temperature associated with a $50 \%$ incidence of discomfort is $93.6^{\circ} \pm 0.4^{\circ} \mathrm{F}$.

Relation between Skin Temperature of Sole and Environmental Temperatures.-It seemed reasonable to expect that the temperature of the skin on the sole, which is so closely related to the thermal comfort of the foot, would be affected, not only by the temperature of the floor, but also by the air temperature, and in order to examine this point the skin temperatures measured at the end of an hour's exposure were correlated with the temperatures of the floor and of the air. Table 2 gives the partial coefficients thus obtained together with the total correlation $(R)$ of skin temperature with the two environmental temperatures.

Table 2 shows that on the whole the skin temperature of the sole tended to be more closely associated with the temperature of the floor surface than with the air temperature. The influence of the latter was not negligible, however, as the constants in the partial regression equations make clear. These constants for equations of the form

$$
\mathrm{t}_{s}=\mathrm{at}_{a}+\mathrm{bt}_{f}+\mathrm{c}
$$

where $t_{s}, t_{a}$, and $t_{f}$ are the temperatures of the skin, the air, and the surface of the floor respectively, are set out in Table 3.

TABLE 3

PARTIAL REGRESSION COEFFICIENTS OF SKIN TEMPERA-

\begin{tabular}{|c|c|c|c|}
\hline \multirow{2}{*}{ Equation for } & \multicolumn{2}{|c|}{$\begin{array}{l}\text { Partial Regression Coefficient of } \\
\text { Skin Temperature on }\end{array}$} & \multirow{2}{*}{$\begin{array}{c}\text { Added } \\
\text { Constant }\end{array}$} \\
\hline & $\begin{array}{c}\text { Air } \\
\text { Temperature }\end{array}$ & $\begin{array}{c}\text { Floor } \\
\text { Temperature }\end{array}$ & \\
\hline 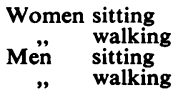 & $\begin{array}{l}0.494 \pm 0.113 \\
0.451 \pm 0.104 \\
0.603 \pm 0.202 \\
0.280 \pm 0.128\end{array}$ & $\begin{array}{l}0.351 \pm 0.039 \\
0.488 \pm 0.109 \\
0.379 \pm 0.121 \\
0.813 \pm 0.145\end{array}$ & $\begin{array}{r}25 \cdot 70 \\
18 \cdot 07 \\
14 \cdot 81 \\
0 \cdot 52\end{array}$ \\
\hline
\end{tabular}
TURE OF THE SOLE ON AIR AND FLOOR-SURFACE TEMPERATURES

The regression constants show that the air temperature had a greater effect when subjects sat than when they walked, that the temperature of the floor surface exerted a greater effect when subjects walked, and that the effect of a given change in air temperature was greater than that of the same change in floor temperature when the subjects sat and less when they walked. The standard errors of the coefficients show, however, that too much stress should not be laid on these indications, for the differences between the coefficients for air temperature and floor temperature in the four equations could be due to chance, although in the equation for men walking that is not very likely. In each of the first three equations the sum of the two regression coefficients is less than unity, indicating that increments of $1^{\circ} \mathrm{F}$. in the temperatures of both the air and the floor surface are accompanied by a rise of rather less than $1^{\circ} \mathrm{F}$. in the temperature of the skin of the sole. In the equation for men walking the sum of the coefficients is greater than unity and it is doubtful whether the equation would fit observations made over a range wider than that covered by the present observations.

Relation between Sensations of Warmth on the Sole and Air and Floor Surface Temperatures.Correlations similar to those just described for the temperature of the skin were also calculated for the sensations of warmth of the sole of the foot after one hour's exposure. The total correlations

\begin{tabular}{|c|c|c|c|c|c|}
\hline \multirow{2}{*}{$\begin{array}{l}\text { Skin Temperature } \\
\text { Correlated with }\end{array}$} & \multirow{2}{*}{ Held Constant } & \multicolumn{2}{|c|}{ Correlation for Women } & \multicolumn{2}{|c|}{ Correlation for Men } \\
\hline & & Sitting & Walking & Sitting & Walking \\
\hline $\begin{array}{l}\text { Air temperature } \\
\text { Floor temperature }\end{array}$ & $\begin{array}{l}\text { Floor temperature } \\
\text { Air temperature }\end{array}$ & $\begin{array}{l}0.288(\mathrm{P}<0.001) \\
0.504(\mathrm{P}<0.001)\end{array}$ & $\begin{array}{l}0.292(\mathrm{P}<0.001) \\
0.299(\mathrm{P}<0.001)\end{array}$ & $\begin{array}{l}0.262(\mathrm{P}<0.01) \\
0.274(\mathrm{P}<0.01)\end{array}$ & $\begin{array}{l}0.141(\mathrm{P}<0.05) \\
0.342(\mathrm{P}<0.001)\end{array}$ \\
\hline \multicolumn{2}{|c|}{$\begin{array}{l}\text { Total correlation (R) of skin temperature with } \\
\text { air and floor surface temperatures }\end{array}$} & 0.546 & 0.674 & 0.469 & 0.594 \\
\hline \multicolumn{2}{|l|}{ No. of experiments } & 240 & 202 & 121 & 238 \\
\hline
\end{tabular}

TABLE 2

PARTIAL CORRELATION OF SKIN TEMPERATURE OF SOLE OF FOOT WITH AIR AND FLOOR SURFACE TEMPERATURES 
(R) of the numerical marks assigned to the sensations of warmth with the temperatures of the air and of the surface of the floor are given below.

\begin{tabular}{c|c}
\hline Subjects and Activity & $\begin{array}{c}\text { Total Correlation (R) of Sensations of } \\
\text { Warmth with Air and Floor Surface } \\
\text { Temperatures }\end{array}$ \\
\hline Women sitting & 0.506 \\
Men walking $\quad$ sitting & 0.624 \\
"w walking & 0.431 \\
\hline
\end{tabular}

The total correlations of sensations with the temperatures of the air and of the floor are all lower than the comparable zero-order correlations of sensations with skin temperature reported earlier in this paper. Each of these correlations is rather smaller than the comparable correlation of skin temperature with the environmental measurements shown in Table 2.

The partial regression coefficients for sensations on air temperature and floor surface temperature, which are set out in Table 4, vary in much the same way as the coefficients for skin temperature shown in Table 3.

TABLE 4

PARTIAL REGRESSION COEFFICIENTS OF SENSATIONS OF WARMTH OF SOLE OF FOOT ON AIR AND FLOOR

\begin{tabular}{|c|c|c|c|}
\hline \multirow{2}{*}{ Equation for } & \multicolumn{2}{|c|}{$\begin{array}{l}\text { Partial Regression Coefficient of } \\
\text { Skin Temperature on }\end{array}$} & \multirow{2}{*}{$\begin{array}{c}\text { Added } \\
\text { Constant }\end{array}$} \\
\hline & $\begin{array}{c}\text { Air } \\
\text { Temperature }\end{array}$ & $\begin{array}{c}\text { Floor } \\
\text { Temperature }\end{array}$ & \\
\hline \begin{tabular}{cl}
\multicolumn{2}{c}{ Women sitting } \\
Men & walking \\
Men & sitting \\
, & walking
\end{tabular} & $\begin{array}{l}0.071 \pm 0.014 \\
0.055 \pm 0.016 \\
0.075 \pm 0.032 \\
0.033 \pm 0.023\end{array}$ & $\begin{array}{l}0.037 \pm 0.005 \\
0.069 \pm 0.020 \\
0.060 \pm 0.019 \\
0.124 \pm 0.028\end{array}$ & $\begin{array}{l}7 \cdot 19 \\
-8.48 \\
-9.48 \\
-11.39\end{array}$ \\
\hline
\end{tabular}

The earlier remarks concerning the regression of skin temperature on the environmental measurements apply also to the figures in Table 4. Although here also air temperature exerts the greater effect on sitting subjects and the floor temperature on walking subjects, the differences between the regression coefficients are not statistically significant and the regression equations should therefore be used with caution.

\section{Discussion}

Maximum Desirable Temperature of a Warmed Floor.-In considering the range of environmental warmth which can be regarded as generally acceptable from the standpoint of general bodily warmth as distinct from the local sensations with which the present paper is concerned, various standards have been adopted by different workers. When comfort investigations are carried out on any considerable number of persons it is commonly found that under no conditions are all the people concerned completely satisfied, and that at the temperature which best suits the greatest number of people some will feel too warm while others will feel too cool. Some workers have taken as acceptable the range of conditions within which sensations of "slightly too warm " to " slightly too cool " were experienced. Others have taken the range within which on a numerical scale of sensations the average value would be "comfortably warm" and " comfortably cool", while yet others have used the range within which not less than $50 \%$ of the votes ranged from " comfortably warm" to " comfortably cool ". It is clear that with the last-mentioned criterion many people will be uncomfortable as the limits of the so-called " comfort zone" are approached and some of the other methods also lead to undesirably wide zones. With these considerations in mind, Bedford (1936) recommended as a practicable comfort zone that range within which, at any temperature, not less than $70 \%$ of the persons were quite comfortable. Within that zone at least $86 \%$ of the comfort votes recorded ranged from "comfortably cool" to " comfortably warm ", so that never more than $14 \%$ of the persons were actually uncomfortable.

While from the standpoint of the general level of warmth it must be accepted that a small proportion of persons may be rather too warm or rather too cool, it is important that the method adopted for warming a room should not be one that is liable needlessly to increase the number of dissatisfied persons by causing local discomfort. In an earlier study of the effects of heated ceilings on comfort (Chrenko, 1953), the experimental subjects reported any feelings of unpleasantness that they experienced while exposed to a heated ceiling. The symptoms of discomfort, usually referred to the head, were variable and very ill-defined. The subjects were asked to report any feelings of unpleasantness, and it may be that in comparison with the usual occupants of an office or other place of work provided with ceiling heating they were hypercritical. However that may be, mildly unpleasant sensations were reported when the intensity of the radiation was very small, and in consequence the recommendations as to the desirable temperatures of heated ceilings of various dimensions were framed on the assumption that, in practice, conditions which caused slight over-warming of the heads of the experimental subjects on $10 \%$ of occasions would be acceptable. In connexion with the experiments on heated floors, however, no such compromise appears to be necessary, for a considerable amount of warming can be achieved by heating the floor to a temperature which, according to the results here reported, is unlikely to occasion even mild discomfort.

The maximum floor temperature at which none 
of the subjects experienced discomfort in these experiments was $77^{\circ} \mathrm{F}$. It should be noted, however, that the probit regression equations (Table 1) suggest that with that floor temperature discomfort might be expected to arise in some 2 or $3 \%$ of observations. Furthermore, the experiments were continued for only one hour and it is possible that while the subjects experienced no discomfort with a floor temperature of $77^{\circ} \mathrm{F}$. in that time, some of them would have been slightly uncomfortable if they had remained on the heated floor for three or four hours. Hence, while the floor temperature should not exceed $77^{\circ} \mathrm{F}$., it would be still better if, except in severe weather, it did not exceed $75^{\circ} \mathrm{F}$.

This finding is in close accord with the view expressed earlier by Bedford (1951) in the light of experience in schools with heated floors. It had been noted that when the surface temperature of the floor did not much exceed $75^{\circ} \mathrm{F}$. the heating seemed satisfactory, but that if the temperature reached $80^{\circ} \mathrm{F}$. the hot floor was tiring to the feet. Hence Bedford concluded that the temperature of a heated floor should not exceed $75^{\circ}$ or perhaps $77^{\circ} \mathrm{F}$. Liese (1951) expressed the view that $77^{\circ} \mathrm{F}$. should be the maximum temperature for a heated floor, and Missenard (1951) and Squassi (1951) allowed a maximum of $82.5^{\circ} \mathrm{F}$. These views are based on general experience of floor heating rather than on experiment. On the other hand, Herrington and Lorenzi (1949) conducted a series of experiments in which the thermal sensations of the subjects were noted and regional skin temperatures measured. They concluded that floor temperatures above $75^{\circ} \mathrm{F}$. were physiologically undesirable and that the local effect of a hot floor was clearly demonstrable when the floor temperature reached $80^{\circ} \mathrm{F}$.

The results for the sitting subjects in this investigation can be compared directly with those obtained by Maréchal (1955), who tested the thermal reactions of 14 women and 17 men when they were sitting. The average air temperature in Maréchal's experiments was $71^{\circ} \mathrm{F}$., or three degrees higher than in the experiments here described. Maréchal pooled the results of his experiments on men and women, presumably because of the variety of the shoes worn, especially that of the women's shoes which, he says, defied classification. Fig. 3 shows the percentage incidence of discomfort among the sitting subjects (men and women) in relation to the temperature of the floor surface (a) for these experiments, and $(b)$ for Maréchal's experiments.

The curves shown in Fig. 3 are derived from the probit regression equations of the incidence of discomfort on floor surface temperature. The equation for Maréchal's results is found to be

$$
\mathrm{P}=0.148 \mathrm{t}_{f}-8.36 \ldots \ldots
$$

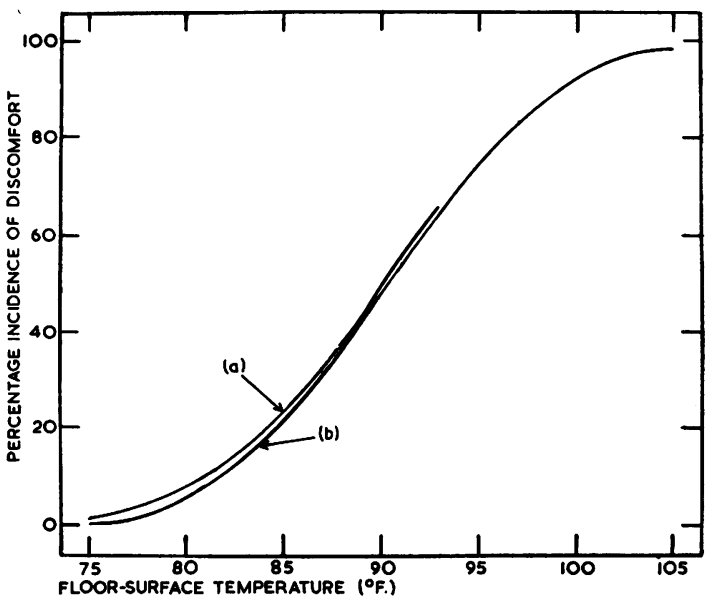

FIG. 3.-The percentage incidence of discomfort in men and women subjects when sitting plotted against the surface temperature of the floor $\left({ }^{\circ} \mathrm{F}.\right)$, curve $(a)$ representing the present experiments and curve $(b)$ the results of Maréchal (1955).

where $\mathbf{P}$ is the probit of the percentage incidence of discomfort and $t_{f}$ is the temperature of the floor surface in ${ }^{\circ} \mathrm{F}$. The corresponding equation for the combined results for men and women in the present experiments is

$$
\mathrm{P}=0 \cdot 142 \mathrm{t}_{f}-7 \cdot 79 \text {. }
$$

The two equations are practically identical and the curves shown in the figure are almost congruent.

It has been remarked earlier that the activity of the subjects seems to be more important than the nature of the footwear, so far as tolerance of a warmed floor is concerned. No attempt was made to classify the shoes worn by our subjects. The soles of the men's shoes were much thicker than those of the women's, yet, after examination of a cut section of a man's worn shoe, it was apparent that estimates of the thickness of the sole based on inspection could be very misleading. Accordingly a special calliper was constructed so that the thicknesses of the soles of intact shoes could be measured. Such measurements showed that the difference between the thicknesses of the soles of men's and women's shoes was much less than had been expected, the average thickness of a man's shoe sole being 0.52 in. and that of a woman's 0.38 in. It seems likely that the somewhat greater tolerance of floor heating shown by the men when they were sitting was mainly due to the effect of the mediumweight woollen socks worn by them, whereas the women wore nylon stockings. The decreased thermal resistance of the men's socks under pressure may account for the similarity of the tolerance of floor heating shown by men and women when walking. 
Attempts have been made to compute the maximum desirable floor temperature from physical parameters. Fischer (1954) made such calculations, assuming that for comfort the skin temperature on the sole of the foot should not exceed $85^{\circ} \mathrm{F}$. with which temperature, according to the present results, the incidence of discomfort would be less than $1 \%$. Fischer concluded that the maximum desirable temperature of the surface of a floor was $77^{\circ} \mathrm{F}$. which agrees with our finding.

Air Temperature and Tolerance of a Warmed Floor.-The average air temperature during the experiments was $68^{\circ} \mathrm{F}$. so that the conclusion that the floor temperature should not exceed $77^{\circ} \mathrm{F}$., or preferably $75^{\circ} \mathrm{F}$., applies to rooms which are maintained at what is commonly regarded in Great Britain as a comfortable indoor temperature. The partial regression coefficients recorded in Tables 3 and 4, however, indicate that the skin temperature and a feeling of warmth on the foot are affected by the temperature of the air as well as by that of the floor. As the air temperature is lowered a higher floor temperature can be tolerated. Although with one exception the partial regression coefficients are statistically significant, the standard errors are rather large, and too much emphasis should not therefore be laid on the values of skin temperature or of warmth sensations calculated from the equations. But it is, nevertheless, of interest to estimate what would be expected to be permissible floor temperatures with air temperatures differing from $68^{\circ} \mathrm{F}$.

For the four groups of observations the average sensations of warmth on the sole of the foot are calculated for an air temperature of $68^{\circ} \mathrm{F}$. and a floor temperature of $77^{\circ} \mathrm{F}$., using the regression constants of Table 4. They do not differ greatly from +0.5 , or midway between exactly "comfortable" and "comfortably warm". Using the sensation values thus ascertained, the floor temperatures which with various air temperatures would be expected to give rise to similar feelings of warmth of the foot have been calculated (Table 5).

Table 5 suggests that in the first three groups a reduction of $10^{\circ} \mathrm{F}$. in the air temperature raises the tolerance of a heated floor considerably. Some doubt has already been expressed about the regression constants for men walking.

Missenard (1955a) obtained results which appeared to show increased tolerance of a warmed floor when the air temperature was lowered, but it is difficult to make a detailed comparison of his results with those of the present experiments owing to differences in the methods of experimentation. In a further paper, however, Missenard (1955b) describes an
TABLE 5

ESTIMATED FLOOR-SURFACE TEMPERATURES GIVING SENSATIONS OF WARMTH ON SOLE SIMILAR TO AN AIR TEMPERATURE $68^{\circ} \mathrm{F}$. AND FLOOR TEMPERATURE $77^{\circ} \mathrm{F}$.

\begin{tabular}{c|c|c|c}
\hline \multirow{2}{*}{$\begin{array}{c}\text { Experimental } \\
\text { Group }\end{array}$} & Estimated & $\begin{array}{c}\text { Floor } \\
\text { Temperature }\left({ }^{\circ} \mathbf{F} \text {.) of }\right.\end{array}$ & Temperature with Air \\
\cline { 2 - 4 } & 60 & 65 & 70 \\
\hline Women sitting & 92 & 83 & 75 \\
Men walking & 84 & 79 & 75 \\
sitting & 87 & 81 & 75 \\
walking & 79 & 78 & 77 \\
\hline
\end{tabular}

experiment in the basilica of St. Quentin. The heating of that building was inadequate and it was decided to heat an area of 20 sq. metres, or about 215 sq. $\mathrm{ft}$., of the floor. When the air temperature was as low as $41^{\circ} \mathrm{F}$. and the heated portion of the floor was at a temperature of $102^{\circ} \mathrm{F}$., only $1 \%$ of that part of the congregation exposed to the heated floor complained of over-warm feet. From the regression constants in Table 4 one can calculate that for sitting persons wearing ordinary indoor clothing the average sensation of warmth on the soles of the feet under such conditions would be -0.2 or -0.5 on our arbitrary scale. This is a gross extrapolation below the range of conditions included in our experiments, but it does appear that when it is not practicable to warm a building to normal standards of comfort severe discomfort from cold feet can be avoided by raising the surface temperature of the floor to a level that would be most undesirable with a higher air temperature.

Changes in Girth of Foot and in Blood Flow.-One criterion for deciding upon the maximum desirable temperature of a floor must be human sensations, and our results show clearly that the sensation of warmth on the sole of the foot is much affected by the temperature of the floor. Yet it is conceivable that a heated floor might exert some other influence of which one was not aware. For instance, it seems possible that when the feet are on a heated floor there may be venous stasis and some swelling of the foot, even though there is no thermal discomfort. An attempt was made to test this. Volume plethysmography was not practicable because it was necessary to carry out the tests under conditions similar to those that prevailed during the main series of experiments. Hence, mercury-in-rubber strain gauges were used to detect any changes in the girths of the instep and ankle.

The results of numerous experiments were indeterminate. In one woman swelling of the feet was detected in a control experiment when the floor was not heated, while no swelling was detected in other subjects when their feet were on a floor heated to an uncomfortably high temperature. 
Allwood and Burry (1954) studied the flow of blood through the feet in relation to the temperature of the water in their plethysmograph. The blood flow was measured by the method of venous occlusion. It was found that the flow increased only slightly with temperature up to about $86^{\circ} \mathrm{F}$., but at higher temperatures it increased markedly. From the probit regression equation for the incidence of discomfort against skin temperature (equation (ii)) it can be seen that at a skin temperature of about $85^{\circ} \mathrm{F}$., which corresponds closely with the $86^{\circ} \mathrm{F}$. at which the blood flow rose sharply, there was in these experiments a sharp rise in the incidence of discomfort. It seems likely, therefore, that in our subjects discomfort through over-warming of the feet was associated with a notable increase in the flow of blood through the feet, even though no consistent evidence of swelling was found. It also seems likely that there was no notable physiological change until discomfort began to appear, so that the thermal sensations may be regarded as a reasonable index of physiological effect.

Skin Temperature and Comfort.- It has been noted earlier that when the results of all the experiments were grouped together there was a highly significant correlation between the skin temperature on the sole of the foot and the local sensation of warmth. The average sensations of warmth reported at various skin temperatures fitted closely about the regression line (equation (i)), but, as one would expect, the individual sensations of the members of a group of people cannot be predicted with any useful degree of accuracy. The regression equation of the probits of the percentage incidences of discomfort on various skin temperatures (equation (ii)) fits the results very well, and gives a reliable indication of the proportion of people who will be uncomfortable. Thus, with a skin temperature of $90^{\circ} \mathrm{F}$. the expected incidence of discomfort is $14 \pm 5 \%$.

A regression equation such as equation (i), which is derived by the method of correlation and in which the dependent variable is the thermal sensation expressed in arbitrary units, enables one to estimate how warm the average person will feel, but it gives no indication of the proportion of people who will be quite comfortable or uncomfortable and this is of importance in considering what should be regarded as limiting conditions. One can, however, arrive at such an indication indirectly by combining equations (i) and (ii) and eliminating $t_{s}$. Thus, from the present observations one obtains the equation

$$
P=2.71 \mathrm{~S}+0.85 \ldots \ldots \ldots \text { (v) }
$$

where $S$ is the mean thermal sensation on the arbitrary scale and $\mathbf{P}$ is the probit of the percentage incidence of discomfort.

Probits estimated from this equation have been converted into percentages and these are plotted against sensations in Fig. 4.

With the sensations of local warmth with which this paper is concerned, with an average sensation of +1.5 or midway between " comfortably warm" and "too warm", the expected incidence of discomfort is about $50 \%$, which agrees with an equation reached by Chrenko (1955) from a consideration of the results obtained by Ellis (1952) in a study of general bodily warmth.

Equation (iii) enables one to estimate the probable incidence of discomfort from estimates of the mean thermal sensations that would be associated with various combinations of air temperature and floor temperature. For the various groups of subjects the constants for the partial regression equations of sensation on air temperature and floor temperature are given in Table 4. If one considers, for example, the women subjects when walking, the calculated mean thermal sensation for an air temperature of $65^{\circ} \mathrm{F}$. and a floor temperature of $75^{\circ} \mathrm{F}$. is +0.3 on the arbitrary scale, while with the same air temperature and a floor temperature of $85^{\circ} \mathrm{F}$. the sensation is $+1 \cdot 0$. According to equation (v), with these mean sensations the probits of the incidence of discomfort are 1.66 and 3.56 respectively, and according to Fig. 4 the percentage incidence of discomfort with the lower floor temperature would be less than $1 \%$, whereas, with the higher one it would be about $7 \%$.

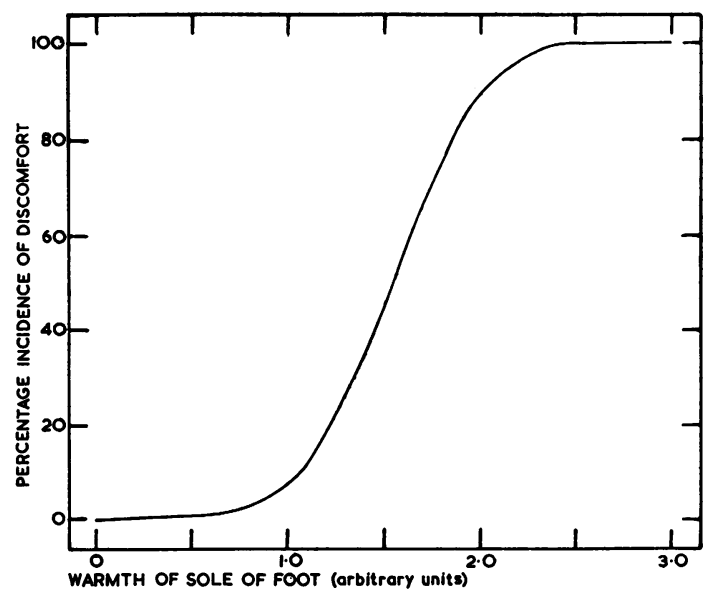

Fig. 4.-The percentage frequency of uncomfortable warming of the sole of the foot plotted against the sensation of the warmth of * the sole expressed in arbitrary units. (Data from all experiments $\because$ combined and warmth of the sole assessed after 60 minutes' -explisure to a heated floor.)

$\therefore$ 


\section{Summary}

Experiments were made on three women and five men who wore their normal shoes and clothing. For one hour they sat with their feet on a heated floor or walked slowly to and fro. Altogether, 379 experiments were made on sitting subjects and 476 on walking subjects.

The average air temperature was $68^{\circ} \mathrm{F}$., but the temperature of different experiments ranged from $58^{\circ} \mathrm{F}$. to $76^{\circ} \mathrm{F}$.

Discomfort arising from over-heating of the floor was due to excessive warming of the feet, as shown by high skin temperatures, especially on the soles. A skin temperature of $93.6^{\circ} \mathrm{F}$. on the sole of the foot was associated with a $50 \%$ incidence of discomfort. A regression equation relating the probable incidence of discomfort to skin temperature is given.

No uncomfortable warming of the feet occurred until the floor temperature exceeded $77^{\circ} \mathrm{F}$., and it is concluded that in a room maintained at a normal temperature the floor temperature should not exceed $77^{\circ} \mathrm{F}$., or, better, $75^{\circ} \mathrm{F}$.

The temperature of the air affects the tolerance of a warm floor, so that a higher floor temperature can be tolerated as the air temperature is lowered. Regression equations are given which relate the average sensation of warmth (expressed on an arbitrary numerical scale) to the temperature of the air and floor.

Mercury-in-rubber strain gauges were used to detect any changes in the girths of the instep and ankle when subjects were exposed to a heated floor. The results were indeterminate. Swelling occurred in one subject when the floor was not heated, while with other subjects there was no swelling when the floor was uncomfortably hot.

The temperature of the skin of the sole at which the incidence of discomfort began to rise rapidly was about the same as that at which a rapid increase in blood flow might be expected.

The results of the present experiments are compared with the conclusions reached in some earlier investigations.

The author's thanks are due to Dr. T. Bedford, Director of the Environmental Hygiene Research Unit, for his advice and helpful criticism during the course of the work, and to all those members of the Unit who kindly volunteered to act as subjects. Especially thanks are due to the Misses R. J. Pearse and B. E. Tredre, who not only acted as subjects, but also gave valuable assistance during the analysis of the results, to Mr. F. E. Smith, M.B.E., for designing and constructing the special calliper used in the experiments, to Dr. R. J. Whitney, who gave advice on the construction and use of his strain gauges, and to Mr. C. R. Underwood, who constructed the bridge used in the experiments with the strain gauges.

\section{REFERENCES}

Allwood, M. J., and Burry, H. S. (1954). J. Physiol. (Lond.), 124, 345. Bedford, T. (1936). Rep. industr. Hlth Res. Board. (Lond.), No. 76. Bedford, T. (1936). Rep. industr. Hith Res. Board. (Lond.), No. 76. Travaux Publics. Equipement technique, No. 17, Nouvelle série, p. 3.

Chrenko, F. A. (1953). J. Instn Heat. Vent. Engrs (Lond.), 20, 375. , (1955). Ibid., 23, 281.

Ellis, F. P. (1952). J., Hyg., (Lond.), 50, 415.

Emmens, C. W. (1948). Principles of Biological Assay. Chapman and Hall, London.

Finney, D. J. (1944). Psychometrika, 9, 31.

, (1947). Probit analysis. University Press, Cambridge.

Fischer, L. J. (1954). J. Instin Heat. Vent. Engrs (Lond.), 21, 445.

General Board of Health (1857). Report by the Commissioners appointed to inquire into the warming and ventilation of dwellings.

appointed to inquire into the warming and ventilation of dwellings.
Herrington, L. P., and Lorenzi, R. J. (1949). Heat. Pip. Air Condit., 21, No. 10 (Öctober), p. 107 .

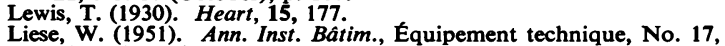

Liese, w. (1951). Ann. Inst. Bátim., Equipement technique, No.
Nouvelle série, p. 9 .

Maréchal, J. C. (1955). Industries Thermiques, No. 7 bis, p. 1085.

Missenard, A. (1951). Ann. Inst. Bâtim., Equipement technique, No. 17.

(1955a). Industries Thermiques, No. 3, p. 5.

-, (1955b). Mem. Soc. Ing. Civils de France, p. 336

Squassi, F. (1951). Ann. Inst. Bâtim., Equipment technique, No. 17 Nouvelle série, p. 14.

Whitney, R. J. (1953). J. Physiol. (Lond.), 121, 1.

Widdows, G. H. (1921). The Builder, 121, 706. 